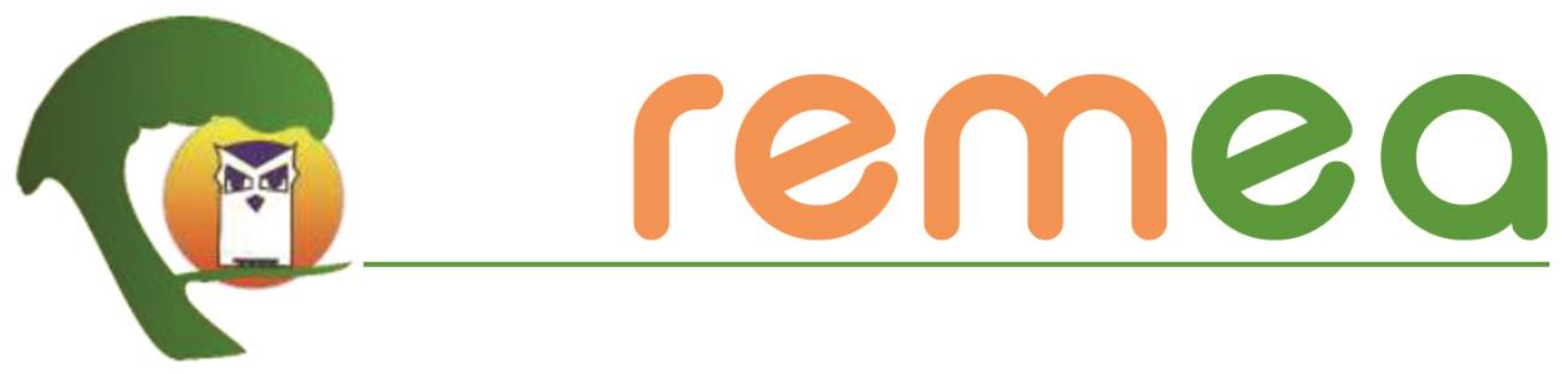

\title{
A educação ambiental em Salas Verdes no estado de São Paulo
}

\author{
Fernanda Nogueira Lopes ${ }^{1}$ \\ Universidade Estadual Paulista Júlio de Mesquita Filho - campus Rio Claro \\ ORCID: https://orcid.org/0000-0003-1829-4433
}

Luiz Carlos Santana

Universidade Estadual Paulista Júlio de Mesquita Filho, campus Rio Claro ORCID: https://orcid.org/0000-0003-4973-2483

Resumo: O Projeto Salas Verdes, do Ministério do Meio Ambiente (MMA), visa atender à Política Nacional de Educação Ambiental (PNEA) com o objetivo de implementar Centros de informação e formação ambiental. Neste trabalho, apresentamos o resultado da análise de dois Projetos Políticos Pedagógicos (PPPs) de Salas Verdes, cujos gestores são uma empresa privada e uma Universidade pública, ambas de São Paulo (SP). Visando identificar, nesse documento, o atendimento à PNEA. Por meio de quatro categorias aglutinadoras dos objetivos e princípios apresentados na política, verificamos o que foi privilegiado e negligenciado na implementação de cada Sala Verde. Os resultados apontam que, nas Salas estudadas, existem lacunas com relação aos princípios e objetivos da PNEA, a exemplo da educação ambiental (EA) integrada com a ciência e tecnologia. Concluímos que o Projeto Salas Verdes é relevante e pode propagar conhecimentos e ações de EA na perspectiva crítica, transformadora e emancipatória que defendemos.

Palavras-chave: Políticas públicas; educação ambiental não formal; Projeto Político Pedagógico.

\section{Educación ambiental en Salas Verdes en el estado de São Paulo}

Resumen: El Proyecto Salas Verdes, del Ministerio del Ambiente (MA), tiene como objetivo dar cumplimiento a la Política Nacional de Educación Ambiental (PNEA) con el objetivo de implementar Centros de información y capacitación ambiental. En este artículo, presentamos el resultado del análisis de dos Proyectos Políticos Pedagógicos (PPP) de Salas Verdes, cuyos gerentes son una empresa privada y una Universidad pública, ambos de São Paulo (SP). Con el objetivo de identificar, en este documento, el cumplimiento de la PNEA. A través de cuatro categorías que aglutinan los objetivos y principios contenidos en la política, verificamos lo privilegiado y descuidado en la implementación de cada Sala Verde. Los resultados muestran que en las Salas estudiadas

1 Ecóloga, Mestra em Educação na linha de educação ambiental pela Unesp Rio Claro. E-mail: feernanda.nl@gmail.com

${ }^{2}$ Docente pesquisador do Programa de Pós-Graduação em Educação do Instituto de Biociências da UNESP de Rio Claro, possui graduação em Filosofia pela Pontifícia Universidade Católica de Campinas (1980), mestrado em Educação pela Universidade Estadual de Campinas (1988) e doutorado em Educação pela mesma universidade (1997). E-mail: luiz.santana@unesp.br 
existen vacíos en relación a los principios y objetivos de la PNEA, como la educación ambiental (EE) integrada con la ciencia y la tecnología. Concluimos que el Proyecto Salas Verdes es relevante y puede difundir conocimientos y acciones de EA en la perspectiva crítica, transformadora y emancipadora que defendemos.

Palabras-clave: Políticas públicas; educación ambiental no formal; Proyecto Político Pedagógico.

\section{Environmental education in Salas Verdes in the state of São Paulo}

Abstract: The Green Rooms, Project of the Environment Ministry (EM), aims to comply with the National Policy on Environmental Education (NPEE) with the objective of implementing environmental information and training Centers. In this paper, we present the result of the analysis of two Pedagogical Political Projects (PPPs) for Green Rooms, whose managers are a private company and a public University, both from São Paulo (SP). In order to identify in this document the fulfillment of the NPEE. Through four categories that bring together the objectives and principles contained in the policy, we verify what was privileged and neglected in the implementation of each Green Room. The results show that in the studied Rooms there are gaps in relation to the principles and objectives of the NPEE, such as Environmental Education (EE) integrated with science and technology. We conclude that the Green Rooms Project is relevant and can spread knowledge and actions of EE in the critical, transformative and emancipatory perspective that we defend.

Keywords: Public policies; no formal environmental education; Pedagogical Political Project.

\section{Introdução}

Por consequência do contexto de crise socioambiental mundial que vivenciamos desde os anos 1960, surgiram e se fortaleceram os movimentos sociais e ambientalistas com ações e lutas políticas em defesa do meio ambiente. As evidências de tal crise socioambiental, provindas da degradação dos elementos naturais pela expansão de um sistema que possui suas bases na exploração da natureza e no acúmulo de capital, têm sido identificadas e demonstram o risco iminente de um colapso ambiental. O risco se coloca, pois, sabe-se que os fundamentos do sistema capitalista são incompatíveis com qualquer ideia de sustentabilidade ecológica (LEFF, 2001; CARVALHO, 2001; PORTO-GONÇALVEZ, 1989).

Os efeitos da crise socioambiental e o debate ambientalista em torno da mesma, além de trazerem novas demandas sociais para os movimentos ambientais e ecológicos, também apresentam a Educação Ambiental (EA) como uma estratégia de enfrentamento do colapso ambiental. Surgiu, assim, um novo campo de conhecimento que visa uma transformação na relação sociedade-natureza, para que a mesma seja mais sustentável, consciente e crítica. Além disso, a EA também é encarada como um importante mecanismo para mediação de conflitos socioambientais e como um instrumento que pode subsidiar a 
criação de espaços de discussão e decisão política realmente democráticos (CARVALHO, 2006; LIMA, 2011; SORRENTINO, 2005; LOUREIRO, 2008).

A crescente valorização e estudo da EA tornou-a presente na formulação de políticas públicas (PPs). As PPs surgem a partir das demandas e interesses sociais e são criadas pelo poder público para solucionar ou amenizar os problemas sociais, dentre eles os de natureza socioambiental. Como exemplo desse processo no Brasil, podemos citar a Política Nacional de Educação Ambiental (PNEA), aprovada em 1999 (BRASIL, 1999).

Para garantir que as PPs sejam implantadas e desenvolvidas com êxito, fazem-se necessárias a avaliação e o acompanhamento da implementação de seus projetos. Esses mecanismos são capazes de estabelecer conexões e mensurar a relação dos objetivos idealizados inicialmente com os impactos resultantes das PPs na sociedade (RUA, 1997).

Com a criação das PPs ambientais e de EA, os estudos sobre elas tornam-se necessários, e os mesmos relacionam-se com a busca por entender que problemas são priorizados na formulação das PPs, quais conflitos busca-se solucionar com tais escolhas, os passos para o processo de efetivação das mesmas, qual o envolvimento dos atores, e quais disputas de interesses se encontram nesse processo. Ressaltamos que, para dar efetividade às PPs, que são leis, existem projetos, programas e ações, e são eles que colocam em prática o que as PPs estabelecem (ANDRADE; SORRENTINO, 2013).

Neste trabalho ${ }^{3}$, buscando contribuir com o campo de pesquisa em EA e com o campo de pesquisa em PPs, analisando o Projeto Salas Verdes, que visa dar efetividade à PNEA por meio da implantação de Centros de informação e formação ambiental (BRASIL, 2002). A investigação foi feita acerca da implementação no estado de São Paulo (SP), a partir de duas Salas com instituições gestoras diferentes entre si, e orientada pelas seguintes questões: as Salas Verdes investigadas estão articuladas com os princípios e objetivos da PNEA? O que está sendo privilegiados e negligenciado, em relação à PNEA, por essas Salas Verdes?

\footnotetext{
${ }^{3}$ Este artigo foi produzido a partir da dissertação de mestrado "A educação ambiental em Salas Verdes no estado de São Paulo" e apresenta parte dos resultados da pesquisa completa.
} 
A partir desses questionamentos, o presente trabalho tem os seguintes objetivos: apresentar os resultados da análise dos Projetos Políticos Pedagógicos (PPPs) de duas Salas Verdes no estado de SP com o propósito de verificar se tais Salas Verdes atendem aos objetivos e princípios apresentados na PNEA.

\section{Fundamentação}

No contexto das PPs no Brasil, a PNEA sendo uma das mais expressivas PPs de EA no país conta com diversos projetos que tem o intuito de atendê-la. Dentre esses, há o Projeto Salas Verdes, criado em 2002 pelo Ministério do Meio Ambiente (MMA), com o objetivo de implementar espaços para o desenvolvimento de atividades educacionais voltadas à temática ambiental, em instituições públicas ou privadas, atuando como Centros de informação e formação ambiental (BRASIL, 2002).

A participação no Projeto se dá por meio da inscrição em editais elaborados e disponibilizados pelo MMA. Não existe um formato único ou modelos pré-definidos para a constituição das Salas Verdes, e cada instituição responsável é livre para implementá-la segundo suas próprias diretrizes. Para a inscrição nos editais há a exigência de construção e constante revisão de um PPP pela instituição interessada na implementação da Sala Verde. O PPP, segundo o próprio MMA (BRASIL, 2002, [s.p.]) “é o que explicita os porquês da Sala Verde; o como, o quando, o onde, o quanto, além de outras questões de cunho político e pedagógico".

Tomando como pressuposto que o Projeto Salas Verdes foi pensado como um conjunto de ações voltado para atender uma PP, nesse caso a PNEA, faz-se necessário pensar o Projeto desse ponto de vista e é de vital importância sua avaliação e acompanhamento. Portanto, buscamos analisar os documentos dos PPPs das Salas selecionadas para este estudo, considerando os princípios e objetivos da mesma conforme preconiza sua Lei no 9795, em seus artigos 4 e 5 (BRASIL, 1999).

Nesse sentido, entendemos que estudos como o apresentado no presente trabalho, contribuem para o entendimento acerca de como uma ação que visa atender uma PP se 
desenvolve em casos particulares, oferecendo pontos de partida para a reflexão acerca da implementação de PPs no estado de SP e acerca de questões teóricas e práticas em relação ao próprio ato político, refletindo sobre os motivos e intenções das escolhas do governo para o desenvolvimento de suas ações (planos, programas e projetos).

\section{Metodologia}

Dentre as Salas Verdes existentes no estado de São Paulo (84 Salas, até o ano de 2019, segundo o Portal Salas Verdes) selecionamos duas como objetos de estudo. A escolha se voltou para a exemplificação de duas diferentes formas de gestão, quais sejam: a) Universidade Pública (UNESP), na cidade de Tupã; b) Empresa privada (General Motors), na cidade de São Caetano do Sul. O propósito dessa escolha foi entender, a partir de casos particulares, como cada tipo de instituição gestora atende aos aspectos da PNEA, por meio das informações contidas nos documentos dos PPPs, e quais deles são privilegiados.

A presente pesquisa foi desenvolvida por meio de uma abordagem qualitativa, e para realizar a análise dos documentos, iniciamos pela leitura dos textos e, ao relacionar essa leitura com as quatro categorias criadas por nós, selecionamos excertos em que há evidência de atendimento aos princípios da PNEA. As categorias aglutinaram o conteúdo apresentado nos Art. 4 e 5 da PNEA (princípios e objetivos), sendo as seguintes: 1) DIA (Democratização da informação e do acesso); 2) CAS (Criticidade acerca do ambiental e do social); 3) IAS (Integração ambiente-sociedade) e 4) EACT (Educação Ambiental integrada à ciência e tecnologia). Selecionamos excertos dos textos dos PPPs onde identificamos relação com cada uma das categorias criadas por nós, e cada um deles foi apresentado com a sigla da categoria correspondente.

O tipo de análise escolhida para os textos dos PPPs foi a análise documental. A técnica da análise documental pode ser definida como um conjunto de interpretações, visando à descrição e representação dos documentos, resultando em algo sistemático para garantir a recuperação da informação. A análise documental realiza-se como um processo de 
transformação do documento e das suas informações, que são, então, interpretadas (IGLESIAS; GÓMEZ, 2004).

\title{
Resultados
}

A Sala Verde do município de Tupã está vinculada à Universidade Estadual Paulista "Júlio de Mesquita Filho", Câmpus de Tupã - Faculdade de Ciências e Engenharia, e faz parte de um projeto de extensão da Universidade. Seu nome é Rede de Educação Ambiental da Alta Paulista (REAP), e sua inauguração se deu no ano de 2018.

O documento do PPP da Sala Verde de Tupã se inicia com uma descrição e contextualização do que é EA e, em um dos excertos voltados a isso, lê-se:

\begin{abstract}
IAS/CAS: A EA busca por meio de um saber socioambiental, pensar, refletir e agir na sociedade de maneira a valorizar a relação ser humano e natureza de forma interdependente, na perspectiva de sociedades sustentáveis e enfoque mais participativo. Nesse contexto, a EA assume cada vez mais a função política e transformadora, na qual a participação e a corresponsabilidade dos indivíduos tornam-se alvos centrais para promover essa nova racionalidade (MORALES et al., 2010; MORALES, 2012 apud UNESP TUPÃ, 2017, p.2, grifos nossos).
\end{abstract}

O excerto apresenta referências de Morales (2010, 2012 apud UNESP TUPÃ, 2017), isso demonstra uma fundamentação teórico-cientifica sobre a EA, apresentada como um campo do conhecimento, o que nos leva a considerar o PPP dessa sala como um documento singular. Os termos destacados no excerto supraindicado (socioambiental, sociedades sustentáveis, função política e transformadora) nos remetem à uma visão crítica de EA, em que há a valorização do debate político integrado ao debate ambiental, com ações transformadoras da realidade, exigindo o questionamento da sociedade e do sistema econômico e social vigente, por meio de um enfoque participativo e crítico (LAYRARGUES; LIMA, 2014).

A Rede de Educação ambiental da Alta Paulista (REAP) foi criada em 2012, com outras frentes de ação e, partindo da experiência acumulada, surgiu o interesse à inscrição no Edital do Projeto Salas Verdes, no ano de 2017. Sendo assim, o PPP aponta que: 
EACT/DIA: A Rede de Educação Ambiental da Alta Paulista (REAP), constituída no ano de 2012, com o intuito de promover reflexão, articulação e discussão da EA no município de Tupã e na região da Alta Paulista vem desenvolvendo atividades ambientais de formação ambiental e contribuindo na articulação entre pessoas e instituições que atuam na área para somar esforços na construção coletiva de práticas e conhecimentos socioambientais locais e regionais no campo da EA (UNESP TUPÃ, 2017, p.2, grifos nossos).

DIA: Dessa forma, criar espaços comuns que contribuam com a disponibilização e democratização de acesso às informações é uma demanda da REAP, bem como do próprio projeto Sala Verde do Ministério do Meio Ambiente (UNESP TUPÃ, 2017, p.2, grifos nossos).

Dito isso, encontra-se aqui a principal justificativa do projeto de extensão REAP em se vincular ao Projeto Salas Verdes, ou seja, gerar maior abrangência da articulação e do debate em torno da EA na região, ampliando as ações da Rede, que atua em toda a região da Alta Paulista e não apenas na Unesp de Tupã ou no município de Tupã. A ideia de "construção coletiva de práticas socioambientais" como apresentado no excerto supracitado, mostra-se interessante por considerar a realidade local/regional e estimular uma construção coletiva de conhecimentos acerca dos problemas socioambientais, considerando a EA também como um campo do conhecimento (UNESP TUPÃ, 2017, p. 2).

Uma EA crítica deve considerar as realidades locais, a partir de uma abordagem que considere todos os aspectos da questão socioambiental, ou seja, um processo educativo de cunho eminentemente político (LAYRARGUES, 2002). No documento do PPP da Sala Verde de Tupã há um foco declarado na articulação da região e na inclusão de ações relacionadas à EA no município de Tupã, inclusive citando a função política e transformadora da mesma, visando politizar o debate ambiental (LAYRARGUES; LIMA, 2014).

Um ponto interessante levantado no item "Histórico e Justificativa" (UNESP TUPÃ, 2017) do PPP é a distância significativa do município de Tupã para a capital do estado de São Paulo, o que, segundo o documento, reflete no acesso às informações e iniciativas relacionadas à questão ambiental:

EACT/DIA: [...] à participação mais efetiva das questões ambientais do Estado de São Paulo, como participar presencialmente e de forma mais ativa da própria Rede de Educação Ambiental Paulista (REAP). Dessa forma, quando se observou que a questão ambiental estava desarticulada na região, bem como tratada de forma periférica, iniciou-se um movimento entre educadores e pesquisadores 
preocupados com a Educação Ambiental para organizar uma rede que pudesse pensar e agir na região de Tupã com foco no princípio da diversidade, respeito às diferenças e na promoção de parcerias para ações colaborativas na EA (UNESP TUPÃ, 2017, p.3, grifos nossos).

Novamente apresenta-se a importância da articulação das ações na região da Alta Paulista com a criação da Rede (REAP), que, a partir da criação da Sala Verde, possui mais um espaço para a consolidação da Rede. A ideia de articulação da região como um todo, e a citação de um movimento entre "educadores e pesquisadores", demonstra a valorização da inclusão da EA articulada com a ciência, trazendo o conhecimento produzido na própria UNESP, e em outras universidades e instituições, para dentro do trabalho na Sala Verde, divulgando-o e possibilitando uma democratização da informação e do acesso.

A REAP se configurava, como dito anteriormente, como um projeto de extensão. No campus da Unesp Tupã, também há um grupo de pesquisa chamado “Pesquisa em Gestão e Educação Ambiental", parceiro da equipe da Sala Verde, inclusive com membros em comum, além de outros grupos de pesquisa da Unesp Tupã, demonstrando importante articulação da ciência com a EA. Vejamos:

$E A C T$ : Isso demonstra que a EA está presente em pesquisas, extensão e ensino na UNESP, Câmpus de Tupã. Mas, além desse grupo, a Sala Verde REAP poderá contar com o auxílio e/ou apoio dos demais grupos de pesquisa da unidade de Tupã, que são: "Grupo de Democracia e Gestão Social"; "Instalações, Ambiência e Bem -star Animal"; "Sistemas Fuzzy Aplicados nas Ciências Agrárias" e "Centro de Pesquisa em Administração e Agronegócio" (UNESP TUPÃ, 2017, p.5).

Como evidenciado no excerto, a gestão da Sala Verde se dá por meio de parcerias com grupos de estudo e de pesquisa da Unesp, indicando que as atividades propostas devem ter embasamento teórico, conhecimento científico, cujos postulados provêm de discussão e reflexão sobre diversos problemas socioambientais sob óticas e perspectivas diferentes, visto que cada grupo trabalha em uma área de conhecimento específica. Importante ressaltar que não é apenas o conhecimento científico que deve ser valorizado, e que não entendemos o mesmo como verdade absoluta, sendo, então, relevante a valorização de outros tipos de conhecimento, por meio do diálogo de saberes, uma ideia apresentada no PPP da Sala Verde de Tupã e valorizada pela gestão da mesma. 
Dentre os objetivos apresentados no PPP para a justificativa da criação da Sala Verde REAP em Tupã, estão os seguintes:

\begin{abstract}
DIA: Somar esforços para a construção de elos representativos de todos os segmentos da sociedade, criando sinergia e diálogo de saberes entre os atores envolvidos em ações, programas e projetos de Educação Ambiental e - contribuir na promoção de parcerias e acordos na construção coletiva de práticas e conhecimentos socioambientais locais e regionais (UNESP TUPÃ, 2017, p.6, grifos nossos).
\end{abstract}

CAS: Para tanto, se faz necessário pensar em espaços de orientação para produção de conhecimentos, habilidades e valores para construção coletiva do aprender as relações entre sociedade e natureza dentro da perspectiva interdisciplinar e apoiada aos princípios sustentáveis (MORALES, 2012 apud UNESP TUPÃ, 2017, p. 5 , grifo nosso).

Apresentam-se, no excerto, ideias interessantes, a exemplo da intenção de representar todos os segmentos da sociedade e a criação de diálogo de saberes. Sabe-se que o diálogo de saberes tem seus fundamentos em uma construção conjunta do conhecimento, uma relação igualitária e horizontal dentre as partes envolvidas, que considera que nenhum conhecimento é melhor do que o outro (LEFF, 2009), ocorrendo sem a imposição de técnicas e receitas prontas para solucionar os possíveis problemas abordados. Por isso se mostra tão importante para o desenvolvimento de uma EA, que se pretenda crítica e emancipatória, mas que não se dá como algo transitório e pontual, pois é um processo contínuo. O excerto trata, também, da perspectiva interdisciplinar, conceito que Japiassu (1976) define como sendo elaborado por meio de uma crítica às fronteiras das disciplinas e de sua compartimentalização. Trata-se, então, de explorar as fronteiras das disciplinas e as zonas intermediárias entre elas, incorporando os conhecimentos de várias áreas (JAPIASSU, 1976).

Nesse sentido, ressaltamos o pensamento de Leff (2009) ao afirmar que para uma interdisciplinaridade ambiental de qualidade não basta a colaboração de mais de um campo do conhecimento científico, havendo necessidade de uma reformulação social e de uma transformação ambiental do conhecimento. O diálogo de saberes e a interdisciplinaridade são, portanto, conceitos importantes para as práticas de EA, e se fazem presentes no PPP da Sala Verde de Tupã. 
Os excertos anteriormente apresentados, de acordo com nossa análise, relacionamse com o que é apresentado na PNEA, principalmente pelo atendimento aos princípios da mesma no enfoque humanista, holístico, democrático e participativo, pela defesa do pluralismo de ideias e da interdisciplinaridade, tendo em vista o fortalecimento de uma consciência crítica sobre a problemática ambiental e social. Além disso, nota-se uma clara relação com a macrotendência crítica (LAYRARGUES; LIMA, 2014), abordando a temática de maneira ampla, inclusiva e politizada.

Acerca do atendimento à PNEA, o texto do PPP, de maneira geral, demonstra grande preocupação com a democratização do acesso e da informação para a sociedade como um todo, principalmente a comunidade externa da Universidade, incluindo-a e divulgando a Sala, suas ações e promovendo a articulação de uma Rede de EA. A EA aparece integrada com a ciência e a tecnologia (categoria EACT) através da parceria com grupos de pesquisa da Universidade, com a participação em encontros científicos e acadêmicos de EA pela equipe da Sala e pela valorização na formação cientifica dos mesmos, o que denota valorização do conhecimento cientifico nas ações, buscando fundamentação teórica e tornando o mesmo acessível, pelo desenvolvimento de uma compreensão integrada do meio ambiente em suas múltiplas e complexas relações, envolvendo aspectos ecológicos, sociais, econômicos, científicos, culturais e éticos, como consta no objetivo I da PNEA.

A integração ambiente e sociedade (categoria IAS) também foi identificada, com menor frequência, mas o texto do PPP como um todo parece apresentar uma abordagem articulada da questão ambiental, com o incentivo à participação individual e coletiva na preservação do equilíbrio do meio ambiente, entendendo-se a defesa da qualidade ambiental como um valor inseparável do exercício da cidadania, como apontam os princípios que a categoria IAS representa.

A Sala Verde de São Caetano do Sul, localizada e gerida pela empresa multinacional General Motors (GM) foi selecionada para essa pesquisa pela particularidade da sua gestão, sendo a única do estado de SP gerida por esse tipo de instituição.

O documento do PPP da Sala Verde da GM foi solicitado à equipe responsável pela gestão do local tanto por e-mail, como presencialmente em uma visita à Sala, no ano de 
2019, mas não foi disponibilizado por, segundo eles, conter informações confidenciais, por questões internas da empresa, e também fomos informadas que a liderança interna responsável não havia liberado o uso do documento para as finalidades da pesquisa.

Sendo assim, sem acesso ao documento, não foi possível realizar a análise documental conforme fizemos para a Sala Verde de Tupã. Devido a isso não foi possível a caracterização do funcionamento da Sala, o conhecimento dos fundamentos teóricos e científicos utilizados como bases para o desenvolvimento do trabalho de EA e do PPP e a identificação se as ações desenvolvidas nessa Sala Verde estão articuladas com objetivos e princípios da PNEA.

\section{Considerações finais}

Inicialmente, ressaltamos que os apontamentos e reflexões elaborados nesta pesquisa não têm a pretensão de serem conclusivos, mas, sobretudo, expressam uma tentativa de compreender como se dá o desenvolvimento do trabalho de EA nas Salas, conhecendo as visões e compreensões de EA apresentadas nos PPPs, e o atendimento ou não aos objetivos da PNEA. A partir de nosso referencial teórico, sabemos que as PPs apresentam profunda relação com a questão social, pois visam atender, por meio de programas e projetos, às necessidades sociais diagnosticadas, podendo gerar mudanças reais e benefícios à sociedade. Por esse motivo, acreditamos que é importante a avaliação de PPs, e de suas ações, para que seja possível realinhar os objetivos e acompanhar os resultados. Acreditamos que esse estudo e seus resultados podem contribuir nesse sentido.

Ao analisarmos o documento disponibilizado (PPP Sala Verde de Tupã) sob o prisma das quatro categorias que englobam os princípios e objetivos da PNEA, encontramos algumas particularidades, sendo possível identificar pontos fracos no Projeto proposto pelo MMA.

No PPP de Tupã a categoria DIA foi a mais frequentemente encontrada (quatro vezes), o que nos leva a entender que a democratização do acesso e da informação é algo valorizado pela gestão dessa Sala Verde, atendendo, significativamente, aos princípios e 
objetivos da PNEA relacionados a essa categoria de análise. Na Sala Verde de Tupã, consideramos como um ponto forte a democratização do acesso e da informação que se dá de maneira expressiva, principalmente em relação à ampliação do conhecimento da população do município de Tupã sobre a Universidade, um objetivo relevante, visto que, muitas vezes, há um distanciamento entre a população e a academia, com consequências negativas, como o baixo índice de aprovação de munícipes no vestibular, entre outros.

A categoria $E A C T$ foi a segunda mais frequente, sendo encontrada três vezes nos excertos selecionados para este estudo. Entendemos que a localização da Sala - em uma Universidade pública (Unesp, no caso) - influenciou no atendimento aos princípios e objetivos da PNEA aos quais a categoria representa pois, sabemos que, no Brasil, as universidades públicas são polos de produção de ciência, principalmente no estado de São Paulo. No entanto, salientamos que a articulação com a ciência e a tecnologia, assim como com outros tipos de conhecimento, é de extrema importância em todos os Centros de formação e informação ambiental, pois é nesses locais, por meio das formações e ações de EA oferecidas, que muitas pessoas, de diferentes faixas etárias e nível socioeconômico, obtém contato com a questão socioambiental e com a EA.

Por esse motivo, mostra-se de extrema importância o oferecimento de uma EA de qualidade, integrada com a ciência e o conhecimento científico tanto do campo da EA quanto do campo da educação, assim como o conhecimento científico da área ambiental, pois entendemos que isso traz embasamento e fomenta o pensamento crítico do público acerca da realidade. Frisamos que não entendemos que é somente o conhecimento científico que deve ser valorizado, e que o mesmo deva ser encarado como única verdade ou como absolutamente neutro. Nossa ênfase está no diálogo de saberes e na troca democrática de informações, considerando e valorizando conhecimentos tradicionais, indígenas, entre outros.

Visto que a categoria IAS foi a menos encontrada nos dados do PPP de Tupã analisados aqui, entendemos que essa baixa frequência da categoria pode indicar a falta de articulação com a PNEA, com uma concepção do meio ambiente em sua totalidade e que considere a interdependência entre o meio natural, o socioeconômico e o cultural, sob o 
enfoque da sustentabilidade e com uma compreensão integrada do meio ambiente em suas múltiplas e complexas relações, envolvendo aspectos ecológicos, psicológicos, legais, políticos, sociais, econômicos, científicos, culturais e éticos, como apontam alguns dos princípios representados pela categoria IAS.

Para que a visão de EA contenha os princípios agrupados pela categoria IAS, e por consequência presentes na PNEA, é necessário vínculo com os ideais da EA crítica, pois uma EA conservadora corrobora com a manutenção do modelo vigente e está relacionada à fragmentação do conhecimento.

Finalmente, na Sala Verde de São Caetano do Sul, gerida pela empresa multinacional General Motors o ponto que nos chamou mais a atenção, primeiramente, foi a não disponibilização do documento do PPP da Sala. Entendemos que o PPP, assim como o acesso à Sala Verde, deve ser público e para todos, pois, faz parte de um Programa de uma PP que visa atender às demandas da população do país. Sendo assim, a não disponibilização do mesmo vai contra os objetivos fundamentais do próprio Projeto Salas Verdes, da PNEA e de outras PPs de EA. Isso não nos impede de concluir que existe a demonstração, aqui, de uma relação do Capital com a EA, tal qual a presença da Sala Verde dentro de uma empresa multinacional como essa, o que indica o não cumprimento dos fundamentos e princípios da EA prescritos pela PNEA e dos descritos no próprio Projeto Salas Verdes.

Um outro ponto emblemático encontrado na Sala da GM foi o prêmio ${ }^{4}$ que a empresa recebeu por conta do "Hotel de Insetos" instalado no espaço da empresa, vinculado à Sala Verde. Segundo notícia vinculada pelo site Revista News, em 9 de novembro de 2019: "Três empresas da GM no Brasil receberam a Certificação Ouro do Wildlife Habitat Council (WHC), graças ao comprometimento com a conservação da biodiversidade e a sustentabilidade das atividades praticadas. O WHC é uma ONG internacional que atua no engajamento e conscientização de empresas em relação à conservação do meio ambiente e da biodiversidade, propondo projetos anuais para as organizações que pretendem tirar a certificação" (NEWS, 2019, p.).

\footnotetext{
${ }^{4}$ Informação obtida pelo site Portal Salas Verdes.
} 
Os prêmios e certificações ambientais como esse são utilizados, muitas vezes, como forma de "marketing verde", dando a ideia de serem sustentáveis, mas mantendo-se dentro do sistema de produção capitalista, quando sabemos que as duas coisas não são compatíveis.

Encontramos, nessa Sala, o exemplo concreto da apropriação privada do que deveria ser público, o que demonstra a falta de compromisso dos gestores e da mantenedora com o que é público e uma distorção do entendimento do próprio conceito de PP, do Projeto e da PNEA.

Apontados tais pontos fracos (falta de atendimento satisfatório em relação a alguns aspectos da PNEA e a apropriação do público pelo privado), ressaltamos que consideramos o Projeto Salas Verdes relevante e, uma vez que sejam feitas adequações por parte do MMA, o mesmo apresenta potencial para propagar conhecimentos e ações de EA na perspectiva crítica, transformadora e emancipatória que defendemos.

\section{Referências}

ANDRADE, Daniel Fonseca de; SORRENTINO, Marcos. Aproximando educadores ambientais de políticas públicas. In SORRENTINO, Marcos (Org.). Educação Ambiental e Políticas Públicas: conceitos, fundamentos e vivências. Curitiba: Appriss, p. 215-223 (Coleção Ambientalismo). 2013. Disponível em:

https://www.researchgate.net/publication/340634086_Aproximando_educadores_ambient ais_de_politicas_publicas. Acesso em: 15 nov. 2021.

BRASIL. Casa Civil. Lei no 9.795, de 27 de abril de 1999. Política Nacional de Educação Ambiental. Brasília: Casa Civil, 1999. Disponível em:

http://www.planalto.gov.br/ccivil_03/leis/19795.htm. Acesso em: 15 nov. 2021.

BRASIL. Ministério do Meio Ambiente. Departamento da Educação Ambiental. Projeto Salas Verdes. Brasília: MMA, 2002. Disponível em: <salasverdes.mma.gov.br> Acesso em 30 jun. 2020.

CARVALHO, Isabel Cristina de Moura. Educação ambiental e Movimentos Sociais: elementos para uma história política do campo ambiental. Educação teoria e prática, Rio Claro, v. 9 n. 16/17, p. 46-56. 2001. Disponível em:

https://www.periodicos.rc.biblioteca.unesp.br/index.php/educacao/article/view/1597. Acesso em: 25 nov. 2021. 
CARVALHO, Luiz Marcelo de. A Temática Ambiental e o Processo Educativo: dimensões e abordagens. In CINQUETTI, Heloisa C. Sisla; LOGAREZZI, Amadeo (Orgs.). Consumo e Resíduos - Fundamentos para o trabalho educativo. São Carlos: EdUFSCar, v. 1, p. 19-41, 2006.

IGLESIAS, María Elinor Dulzaides; GÓMEZ, Ana María Molina. Análisis documental y de información: dos componentes de un mismo proceso. ACIMED, La Habana, v. 12, n. 2, p. 1-5, 2004. Disponível em: http://eprints.rclis.org/5013/. Acesso em 25 nov. 2021.

JAPIASSU, Hilton. Interdisciplinaridade e a Patologia do Saber. Rio de Janeiro: Imago, 1976.

LAYRARGUES, Philippe Pomier. Educação para a gestão ambiental: a cidadania no enfrentamento político dos conflitos socioambientais. In LOUREIRO, Carlos Frederico B. (Org.). Sociedade e meio ambiente: a educação ambiental em debate. 3. ed. São Paulo: Cortez, p. 87-155. 2002.

LAYRARGUES, Philippe Pomier; LIMA, Gustavo Ferreira da Costa. As macrotendências político-pedagógicas da educação ambiental brasileira. Ambiente \& Sociedade, São Paulo, v. 17, n. 1, p. 23-40, 2014. Disponível em:

https://www.scielo.br/j/asoc/a/8FP6nynhjdZ4hYdqVFdYRtx/?lang=pt. Acesso em: 25 nov. 2021.

LEFF, Enrique. Saber ambiental: sustentabilidade, racionalidade, complexidade e poder. Tradução de Lúcia Mathilde Endlich Orth. Petrópolis: Vozes, 2001.

LEFF, Enrique. Complexidade, racionalidade ambiental e diálogo de saberes. Educação \& Realidade, Porto Alegre, v. 34, n. 3, p. 17-24. set/dez. 2009. Disponível em:

https://seer.ufrgs.br/educacaoerealidade/article/view/9515/6720. Acesso em 25 nov. 2021.

LIMA, Gustavo Ferreira da Costa. Educação ambiental: formação, identidades e desafios. Campinas: Papirus, 2011.

LOUREIRO, Carlos Frederico Bernardo; CUNHA, Cláudia Conceição. Educação ambiental e gestão participativa de unidades de conservação: elementos para se pensar a sustentabilidade democrática. Ambiente \& Sociedade, São Paulo, v. 11, n. 2, p. 237-253, 2008. Disponível em:

https://www.scielo.br/j/asoc/a/xT99ttVXqTpmsY3XcZvYfMv/?format=pdf\&lang=pt. Acesso em: 25 nov. 2021.

PORTO-GONÇALVES, Carlos Walter. Os (des) caminhos do meio ambiente. São Paulo: Contexto, 1989. 
RUA, Maria das Graças. Análise de políticas públicas: conceitos básicos. Manuscrito, elaborado para el Programa de Apoyo a la Gerencia Social en Brasil. Brasília. Banco Interamericano de Desarrollo - INDES, 1997.

SORRENTINO, Marcos et al. Educação ambiental como política pública. Educação e pesquisa, São Paulo, v. 31, n. 2, p. 285-299, 2005. Disponível em:

https://www.scielo.br/j/ep/a/WMXKtTbHxzVcgFmRybWtKrr/?format=pdf. Acesso em: 25 nov. 2021.

TRÊS FÁBRICAS da GM no Brasil recebem certificação ouro do WHC. Revista News. São Caetano do Sul, 9 de novembro de 2019. Destaque. Disponível em:

https://revistanews.com.br/2019/01/10/tres-fabricas-da-gm-no-brasil-recebem-certificacaoouro-do-whc/. Acesso em: 15 nov. 2021.

UNIVERSIDADE ESTADUAL PAULISTA - UNESP. Faculdade de Ciências e Engenharia. Câmpus Tupã. Projeto Político Pedagógico da Sala Verde. Tupã: UNESP, 2017. 